https://helda.helsinki.fi

Cardiac function after cardiac arrest : what do we know?

Babini, Giovanni

2021-03

Babini , G , Ameloot , K \& Skrifvars , M 2021, ' Cardiac function after cardiac arrest : what do we know? ' , Minerva Anestesiologica , vol. 87 , no. 3 , pp. 358-367 . https://doi.org/10.23736/S0375-9393.20.145

http://hdl.handle.net/10138/334519

https://doi.org/10.23736/S0375-9393.20.14574-7

unspecified

acceptedVersion

Downloaded from Helda, University of Helsinki institutional repository.

This is an electronic reprint of the original article.

This reprint may differ from the original in pagination and typographic detail.

Please cite the original version. 


\title{
Cardiac function after cardiac arrest - What do we know?
}

\author{
Giovanni BABINI ${ }^{1,2}$, Koen AMELOOT ${ }^{3}$, Markus B. SKRIFVARS ${ }^{2} *$
}

${ }^{1}$ Department of Pathophysiology and Transplantation, University of Milan, Milan, Italy

${ }^{2}$ Department of Emergency Medicine and Services, University of Helsinki and Helsinki University Hospital, Helsinki, Finland

${ }^{3}$ Department of Cardiology, Ziekenhuis Oost-Limburg, Genk, Belgium

Department of Cardiology, University Hospitals Leuven, Leuven, Belgium

Faculty of Medicine and Life Sciences, University Hasselt, Diepenbeek, Belgium

\section{Corresponding author}

Markus B. Skrifvars, MD, PhD, EDIC, FCICM

Department of Anaesthesiology, Intensive Care and Pain Medicine, University of Helsinki and Helsinki University Hospital, Haartmaninkatu 4, 00029, Helsinki, Finland

E-mail addresses: markus.skrifvars@ @us.fi, markus.skrifvars@ @elsinki.fi 


\begin{abstract}
Post-cardiac arrest myocardial dysfunction (PCAMD) is a frequent complication faced during postresuscitation care that adversely impacts survival and neurological outcome. Both mechanical and electrical factors contribute to the occurrence of PCAMD. Pre-arrest ventricular function, the cause of cardiac arrest, global ischaemia, resuscitation factors, ischaemia/reperfusion injury and postresuscitation treatments contribute to the severity of PCMAD. The pathophysiology of PCAMD is complex and include myocytes energy failure, impaired contractility, cardiac oedema, mitochondrial damage, activation of inflammatory pathways and the coagulation cascade, persistent ischaemic injury and myocardial stiffness.

Hypotension and low cardiac output with vasopressor/inotropes need are frequent after resuscitation. However, clinical, hemodynamic and laboratory signs of shock are frequently altered by cardiac arrest pathophysiology and post-resuscitation treatment, potentially being misleading and not fully reflecting the severity of post-cardiac arrest syndrome. Even if validated criteria are lacking, an extensive haemodynamic evaluation is useful to define a "benign" and a "malign" form of myocardial dysfunction and circulatory shock, potentially having treatment and prognostic implications. Cardiac output is frequently decreased after cardiac arrest, particularly in patients treated with target temperature management (TTM); however, it's not independently associated with outcome. Sinus bradycardia during TTM seems independently associated with survival and good neurological outcome, representing a promising prognostic indicator. Higher mean arterial pressure (MAP) seems to be associated with improved survival and cerebral function after cardiac arrest; however, two recent randomized clinical trials failed to replicate these results. Recommendations on haemodynamic optimization are relatively poor and are largely based on general principle of intensive care medicine.
\end{abstract}

Key words: cardiac arrest, myocardial dysfunction, post-cardiac arrest syndrome 


\section{Introduction}

Cardiac arrest (CA) is a leading cause of death in Europe and has an incidence of 84.0-88.6 cases per 100,000 adults every year, with survival rates of only 8-10\% and few with good neurological outcomes. ${ }^{1,2}$ Despite significant improvements in resuscitation and post-resuscitation care, CA survival has only slightly increased. ${ }^{3}$ About half of the patients admitted alive in hospital die before discharge, and even fewer show good long-term neurological outcomes. ${ }^{4}$ Poor prognosis is due to post-CA syndrome (PCAS), a pathophysiological state that includes post-CA myocardial dysfunction (PCAMD) and cerebral injury and is related to the whole-body ischaemia-reperfusion (I/R) injury. ${ }^{4}$

PCAMD is a complex condition where pre-arrest ventricular function, the cause of CA, global ischaemia, resuscitation factors, I/R injury and post-CA treatments contribute to the severity of myocardial injury and cardiac dysfunction. ${ }^{4-7}$ Haemodynamic instability requiring pharmacological/mechanical support occurs in two thirds of CA patients with ventricular fibrillation. ${ }^{8}$ If not promptly recognized and treated, this clinical condition can deteriorate, causing multiorgan dysfunction and early death. ${ }^{4,9,10}$ In patients that survive to hospital discharge, poor cerebral perfusion and ischaemia during intensive care unit stay exacerbates the neurological injury. ${ }^{4}$

The mechanisms of PCAMD overlap with those observed in other clinical syndromes, such as myocardial infarction, sepsis-induced cardiomyopathy and stress-related cardiomyopathy (i.e. Tako-Tsubo syndrome), and after cardiopulmonary bypass. Nonetheless, PCAMD has a typical time course and features that need to be considered in order to provide comprehensive care. ${ }^{4,6,7}$

\section{Pathophysiology of myocardial dysfunction after CA}

PCAMD is defined as a reversible deterioration of cardiac performance that occurs after return of spontaneous circulation (ROSC), not fully explained by myocardial ischaemia or persistent coronary occlusion. As opposed to the regional distribution of myocardial wall dyskinesis in acute myocardial infarction, PCAMD impacts the heart globally. Both mechanical and electrical factors contribute to the occurrence of PCAMD; typical features include severe impairment in systolic and diastolic function and cardiac dysrhythmias and recurrent CA. ${ }^{11}$ PCAMD overlaps with pre-arrest cardiac performance and myocytes necrosis, due to coronary ischaemia and I/R injury, so it is particularly tricky to accurately distinguish between reversible and irreversible myocardial injury. 


\section{Cardiac arrest}

Decrease in oxygen delivery shifts cellular metabolism to non-oxidative glycolysis, decreasing ATP production and causing intracellular acidosis and sodium imbalance due to $\mathrm{Na}^{+} / \mathrm{K}^{+}$ATPase inhibition; furthermore, accumulated $\mathrm{H}^{+}$activates the sarcolemmal sodium-hydrogen exchanger isoform-1, worsening $\mathrm{Na}^{+}$overloads. ${ }^{12}$ Increase in cytosolic sodium causes cell swelling and promotes intracellular $\mathrm{Ca}^{2+}$ influx through $\mathrm{Na}^{+} / \mathrm{Ca}^{2+}$ exchangers; ATP deficit impairs the activity of both plasma membrane calcium ATPase and sarco-/endoplasmatic reticulum calcium ATPase, further exacerbating $\mathrm{Ca}^{2+}$ overload. Calcium overload promotes apoptosis by caspases activation, activates intracellular proteases/phospholipases and initiates the formation of the mitochondrial permeability transition pore. Global hypoperfusion and ischaemia trigger a whole-body inflammatory response, aggravating mitochondrial injury, damaging membrane phospholipids and impairing fatty acid metabolism. Finally, endothelial damage and initiation of the coagulation cascade occur, causing neutrophil and platelet adhesion and microthrombi formation in peripheral microcirculation.

\section{During cardiopulmonary resuscitation}

Chest compression efficacy is intrinsically limited, and the resulting heart perfusion is not enough to revert cardiac ischaemia. Cardiac stiffening caused by prolonged ischaemia (i.e. "stone heart") and by progressive dilatation of the ventricles during $\mathrm{CPR}^{13}$ impairs the blood flow generated during chest compressions. Microthrombosis and leucocyte adhesion will further impede myocardial reperfusion (i.e. "no-reflow phenomenon"). ${ }^{14}$ High levels of circulating adrenaline bind with $\beta$-2 receptors, coupled with inhibitory $G$ proteins, and decrease contractility; ${ }^{15}$ furthermore, catecholamines cause microvascular coronary vasoconstriction, increase oxygen consumption and exacerbate oxidative stress, intensifying the severity of PCAMD. ${ }^{16}$ Cardiac defibrillation contributes to myocardial injury proportional to the energy and the number of shocks delivered. ${ }^{17,18}$

\section{After return of spontaneous circulation}

The detrimental effects initiated during CA continue after ROSC, particularly in the first hours after resuscitation. Indeed, the restoration of tissue perfusion initially paradoxically aggravates the I/R injury due to overproduction of reactive oxygen species (ROS), further impairing beta-adrenergic signalling and ATP production in the heart. Cytokines released have direct negative inotropic effects and intensify cellular energy failure and ROS production. ${ }^{19}$ Glycolysis is persistently uncoupled from oxidative phosphorylation, worsening intracellular acidosis and impairing myocyte contractile function. Persistently high levels of intracellular $\mathrm{Ca}^{2+}$ and circulating catecholamines 
aggravate the potential for cardiac dysrhythmia and recurrent CA. Cell metabolism starts to improve 3-6 hours after ROSC, due to enhanced ATP and antioxidant production. Ion pumps and cellular enzymes increase their functionality, restoring intracellular $\mathrm{Na}^{+}$and $\mathrm{Ca}^{2+}$ normal concentrations. The fading of the "no-reflow" phenomenon, the catabolism of circulating catecholamines and a decrease in $\mathrm{H}^{+}$concentration increase the sensitivity of contractile proteins to $\mathrm{Ca}^{2+}$ and ameliorate cardiac contractility. Generally, the alterations associated with PCAMD resolve in the next 24-72 hours, even if longer recovery has been reported. ${ }^{20}$

\section{Cardiac and haemodynamic characteristics after CA}

After CA, patients frequently exhibit various degrees of haemodynamic instability and hypotension, requiring advanced haemodynamic monitoring, aggressive fluid replacement, vasopressor/inotropic drugs and, in selected cases, mechanical support of the circulation. ${ }^{7,11,21}$ As in other clinical conditions, haemodynamic optimization has become a cornerstone of post-resuscitation care, ${ }^{22}$ however, the level of evidence is scarce, and the impact on the outcome is unclear, ${ }^{23-25}$ representing a relevant knowledge gap in resuscitation science. ${ }^{26}$

Soon after resuscitation, the heart rate and arterial pressure are elevated, due to high concentrations of endogenous and exogenous catecholamines. The heart shows signs of both diastolic dysfunction (cardiac oedema, ischaemic contracture and impaired relaxation) and systolic dysfunction (impaired contractility, inadequate oxygen delivery, intracellular acid-base and ion imbalance); as a result, cardiac output is generally decreased and patients may manifest with hypotension, low cardiac output and poor tissue perfusion (i.e. cardiogenic shock). ${ }^{27}$ Moreover, distributive shock may overlap with cardiogenic shock, due to superimposed vasodilation secondary to I/R injury and systemic inflammation, requiring volume expansion and prolonged vasopressor support. ${ }^{4,9}$

\section{Defining cardiogenic shock in the post-cardiac arrest patient}

A clear impediment for the research of cardiac dysfunction after CA is the lack of well validated criteria to define cardiogenic shock. Criteria such as hypotension (i.e. systolic blood pressure $<90$ $\mathrm{mmHg}$, or vasopressors required to achieve a blood pressure $\geq 90 \mathrm{mmHg}$ ), signs of impaired organ perfusion (e.g. central nervous system abnormalities including confusion, lack of alertness or loss of consciousness; oliguria; cold, clammy skin and extremities; increased arterial lactate $>2 \mathrm{mmol} \mathrm{l}^{-1}$ ) in the state of normo- or hypervolaemia and reduced cardiac index (CI, i.e. $<1.8$ or $<2.21 \mathrm{~min}^{-1} \mathrm{~m}^{-2}$ with cardiac support) or elevated left ventricular filling pressures (i.e. pulmonary capillary wedge pressure $>15 \mathrm{mmHg}$ ) are not useful. ${ }^{28}$ Indeed, all CA patients have high blood lactate at admission 
to the hospital, and patients receive target temperature management (TTM), resulting in cool extremities, skin mottling and hypothermic diuresis. In addition, patients receive sedative and neuromuscular-blocking agents, which makes neurological evaluation impossible. Lactate may also be a poor indicator of tissue oxygenation in post-CA patients, since gut ischaemia and seizures may increase serum lactate levels, and hypothermia may reduce lactate clearance by the liver. ${ }^{29}$

General criteria for adequate perfusion include lactate clearance and adequate diuresis. ${ }^{22}$ However, normal serum lactate levels do not guarantee optimal brain oxygenation. Therefore, low cardiac output is easily undetected if advanced haemodynamic monitoring is not used. ${ }^{8}$

\section{Cardiac output}

Low cardiac output is present in up to two thirds of CA patients, ${ }^{8,9}$ particularly in those with a cardiac cause of the CA. ${ }^{8,30}$ Some studies indicate that it accounts for most of the early death in the ICU in the first three days. ${ }^{10}$ Typically, the patients are in cardiogenic shock and suffer from low diastolic pressure, causing coronary hypoperfusion with a progressive lowering of cardiac output, ultimately resulting in multiple organ failure, refractory shock and death. ${ }^{5,9}$ It has been reported that cardiac output remains depressed for $8 \mathrm{~h}$ after ROSC and progressively recovers in the next 24$48 \mathrm{~h}$, demonstrating the reversible nature of PCAMD in patients without large acute myocardial infarction (AMI) as the precipitating cause of CA. ${ }^{9}$ These data are consistent with numerous experimental reports. ${ }^{31-33}$ Patients with pre-existing cardiac dysfunction have lower postresuscitation echocardiographic left ventricular ejection fraction (LVEF) and cardiac output compared to the healthy population; however, the relative decline in LVEF from baseline values is similar in both patient groups. ${ }^{34}$ Adequate measurement of cardiac output by continuous thermodilution may be challenging when intravascular cooling devices are used, and continuous mixed venous oxygen $\left(\mathrm{SvO}_{2}\right)$ saturation may better reflect the cellular oxygen balance. ${ }^{35}$ Various studies have questioned the impact of cardiac output on resuscitation outcomes. In a subgroup analysis from the TTM trial, cardiac index during TTM after CA was not associated with mortality or cause of death (cerebral vs. non-neurological) regardless of the level of the TTM target temperature (Table I) ${ }^{36}$ Nonetheless, haemodynamic profiles of patients dying from nonneurological death significantly differed compared to survivors and cerebral deaths, showing that reduced mean arterial pressure and elevated lactate were independent predictors of non-neurological mortality. Even if the cardiac index was not a mortality predictor by itself, the presence of CI $<2.51$ $\min ^{-1} \mathrm{~m}^{-2}$ and blood lactate $>2 \mathrm{mmol}^{-1}$ identified patients with higher mortality. Similarly, cardiac output failed to predict the incidence of acute kidney failure and the need for renal replacement 
therapy, whereas heart rate, lactate levels and mean arterial pressure were better predictors (Table I). ${ }^{37}$

Post-resuscitation care (including hypothermia, sedation, analgesia, paralysis and mechanical ventilation) may affect cardiac output independently of the extent of myocardial injury and PCAMD. Indeed, patients treated with TTM (deeply sedated and frequently paralyzed) reduce cellular metabolism and oxygen consumption, so even low cardiac output may guarantee adequate oxygen delivery. Moreover, superimposed vasodilation may deceptively increase cardiac output without any improvement in tissue perfusion. ${ }^{4,9}$ In fact, a preserved or augmented CI does not exclude the presence of extensive microcirculatory alterations, resulting in regional hypoperfusion and organ dysfunction. ${ }^{27}$

\section{Heart rate}

Heart rate has been associated with outcome in CA patients; somewhat surprisingly, sinus bradycardia during TTM has been shown to be associated with lower mortality and less severe organ dysfunction (Table I). ${ }^{38,39}$ Moreover, lower time-weighted mean heart rates at 48- and 72hours post-resuscitation were associated with improved one-year neurological outcomes, even if the relationship was less marked in TTM patients. ${ }^{40}$ Hypothermia can modify the heart rate through various mechanisms; after an initial phase of tachycardia, the heart rate progressively decreases, due to alterations in the spontaneous depolarization of cardiac pacemaker cells, in the conduction of myocardial impulses, in the duration of action potentials and in autonomic nervous system function during the maintenance phase of TTM. Moreover, by reducing oxygen consumption, a decrease in oxygen delivery is relatively well tolerated. Sinus bradycardia probably represents a marker of preserved autonomic response, and the lack of this reflex could identify patients with more severe PCAS and greater neurological injury. ${ }^{39,40}$ The crosstalk between heart rate and autonomic function (e.g. the heart rate variability ${ }^{41}$ and the haemodynamic response during different phases of hypothermia $^{42}$ ) is a topic of growing interest. No prospective trial has evaluated potential strategies to reduce heart rate during post-resuscitation care, so it is unclear if lower heart rate represents a prognostic marker or could be a future treatment target. Interestingly, a right bundle branch block recording in the first ECG at hospital admission was directly associated with higher mortality and was independently associated with an unfavourable prognosis $;{ }^{43}$ however, further investigations are needed to confirm these results.

\section{Arterial pressure}


Mean arterial pressure (MAP) has been widely investigated as a potential haemodynamic goal in post-resuscitation care, and various studies reported a positive association between MAP and outcome (Table I) ${ }^{44-46}$ Furthermore, MAP $<65-70 \mathrm{mmHg}$ and higher doses of vasopressor were associated with increased incidence of organ dysfunction (e.g. acute kidney injury), mortality and a poor neurological outcome. ${ }^{45,47-50}$ Two prospective randomized clinical trials (COMACARE ${ }^{51}$ and Neuroprotect post- $\mathrm{CA}^{52}$ trials; Table I) compared the impact of higher MAP $(80-100 \mathrm{mmHg}$ and 85-100 mmHg with $\mathrm{SvO}_{2}$ 65-75\%) with low-normal MAP values (65-75 mmHg and $65 \mathrm{mmHg}$, respectively); in both studies, a haemodynamic strategy with higher MAP was feasible and safe; however, no improvements in neurological outcome were observed at 180 days. ${ }^{51,52}$ However, higher MAP was associated with lower plasma cardiac troponin T levels when data from both studies were merged, suggesting that a balanced use of $\alpha-1$ vasoconstrictor could increase coronary perfusion pressure and ameliorate myocardial ischaemia without significant side effects (personal communication from Pekka Jakkula).

Targeting higher MAP values has a pathophysiological rationale, particularly in the immediate hours after resuscitation. Cerebral perfusion is severely impaired, due to intracerebral vasoconstriction, high circulating catecholamines, persistent vascular occlusion, a right-shift of cerebral autoregulation limits and a heterogeneous distribution of blood flow; ${ }^{14,53,54}$ concordantly, a higher MAP should better preserve cerebral blood flow. However, the evidence is limited regarding this hypothesis. Even if no target arterial pressure can be recommended, a MAP > 65-70 $\mathrm{mmHg}$ seems reasonably safe and consistent with similar recommendations in critical care. Possibly, a fixed MAP value simply does not fit every patient need, and a personalized approach based on individual comorbidities and physiological response should be encouraged. ${ }^{50-52}$

\section{Practical considerations}

Cardiac output by itself may not be the best indicator to identify patients with increased risk of mortality and poor long-term neurological function. However, when cardiac function is contextualized with other clinical, haemodynamic and laboratory variables, two distinct haemodynamic phenotypes could be observed in patients with low cardiac output at admission: a "benign" and a "malign" form of myocardial dysfunction and cardiogenic shock (Table II). It is important to recognize these two different patterns, because they potentially have treatment and prognostic implications (Figure 1). 
Recommendations on haemodynamic optimization are relatively poor and are largely based on general principle. ${ }^{22}$ An echocardiogram should be obtained as early as possible, ideally on admission; serial echocardiographic evaluation allows continuous monitoring and treatment titration. Cerebral tissue oxygen saturation as measured with near infrared spectroscopy did not show a good correlation with prognosis. In the absence of good indicators of adequate cerebral and vital organ oxygenation, treatment should be guided by haemodynamic variables (e.g. blood pressure, heart rate, urine output, rate of lactate clearance and central venous oxygen saturation), taking into consideration their specific limitations, as previously discussed. In intensive care, an arterial line for continuous blood pressure monitoring is essential, and a central venous access is also indispensable for blood sampling, blood gas analysis and drug administration. Advanced cardiac output monitoring should be considered in patients with a malign form of cardiogenic shock, and the choice of a specific device/technology should be based on local availability and expertise.

The best treatment strategy to optimize cardiac function is still debated. Faster lactate clearance and improved outcomes were observed when a higher MAP was achieved using fluid over vasopressors. ${ }^{55}$ Even if it is not possible to exclude that this is feasible in less severely injured patients, abundant fluid resuscitation in the first hours after resuscitation is frequent and remarkably well tolerated. ${ }^{9,23}$ Vasopressors are used to target MAP and limit positive fluid balance. No specific drug demonstrated a clear advantage; however, the use of adrenaline is likely best avoided. In a recent randomized controlled pilot trial, the use of adrenaline compared to noradrenaline in AMI patients resulted in more tachycardia, refractory cardiogenic shock, multiple organ dysfunction and mortality, probably due to catecholamine overload and stress cardiomyopathy. ${ }^{15,56,57}$ Currently, noradrenaline is the first-line vasopressor to maintain target MAP. One should, however, be careful using unopposed $\alpha-1$ induced vasoconstriction, since elevated afterload may impair stroke volume, cardiac output and cerebral perfusion. A combined approach using vasopressors and inotropes, as guided by continuous $\mathrm{SvO}_{2}$ measurements, has been tested in the Neuroprotect post-CA trial and resulted in clear improvements in cerebral perfusion and oxygenation during the first 12 hours of ICU stay. ${ }^{52}$ Other inotropes have been proposed (e.g. levosimendan, PDE-III inhibitors) and represent valid alternatives in selected patients. ${ }^{11}$ Mechanical circulatory support (e.g. intra-aortic balloon pump, percutaneous ventricular assist device and extracorporeal life support) should be promptly inserted in selected patients when pharmacological therapies fail..$^{21,58}$ 
Fast-track coronary angiography $(\mathrm{CAG})$ and percutaneous coronary intervention (PCI) are indicated for patients presenting ST-segment-elevated myocardial infarction (STEMI) on post-resuscitation ECG. ${ }^{59,60}$ Early reperfusion is associated with improved survival and good neurological outcomes. ${ }^{61}$ In patients without STEMI, non-coronary causes of CA should be excluded. ${ }^{59,60}$ If alternative causes are not identified, delayed CAG and PCI are indicated, ideally within two hours, since an acute critical coronary occlusion could be identified in up to one third of the patients. ${ }^{61}$ The role of CAG and PCI in this group of patients is less well established, and recent evidence does not support any clear impact on CA outcome. ${ }^{62}$

\section{Key messages}

- Post-cardiac arrest myocardial dysfunction frequently complicates post-resuscitation care and adversely impacts survival and neurological outcome.

- Clinical criteria to define cardiogenic shock are not validated in cardiac arrest population; indeed, low cardiac output is frequent and not independently associated with mortality or adverse outcome.

- Two distinct haemodynamic phenotypes could be observed in patients with PCAMD and low cardiac output at admission: a "benign" and a "malign" form of myocardial dysfunction and cardiogenic shock.

- Evidence on best treatment strategy for haemodynamic optimization after cardiac arrest is scarce; actual recommendations are largely based on general principles of haemodynamic support in critically ill patients. 


\section{References}

1. Gräsner J-T, Lefering R, Koster RW, Masterson S, Böttiger BW, Herlitz J et al. EuReCa ONE - 27 Nations, ONE Europe, ONE Registry: A prospective one month analysis of outof-hospital cardiac arrest outcomes in 27 countries in Europe on behalf of EuReCa ONE Collaborators 1. Resuscitation 2016;105:188-95.

2. Gräsner JT, Wnent J, Herlitz J, Perkins GD, Lefering R, Tjelmeland I et al. Survival after out-of-hospital cardiac arrest in Europe - results of the EuReCa TWO study. Resuscitation 2020;148:218-26.

3. Chan PS, McNally B, Tang F, Kellermann A. Recent trends in survival from out-of-hospital cardiac arrest in the United States. Circulation 2014;130:1876-82.

4. Nolan JP, Neumar RW, Adrie C, Aibiki M, Berg RA, Böttiger BW et al. Post-cardiac arrest syndrome: epidemiology, pathophysiology, treatment, and prognostication. Resuscitation 2008;79:350-79.

5. Cerchiari EL, Safarb P, Kleinc E, Cantadorea R, Pinskyd M. Cardiovascular function and neurologic outcome after cardiac arrest in dogs. The cardiovascular post-resuscitation syndrome. Resuscitation 1993;25:9-33.

6. Chalkias A, Xanthos T. Pathophysiology and pathogenesis of post-resuscitation myocardial stunning. Heart Fail Rev 2012;17:117-28.

7. Jentzer JC, Chonde MD, Dezfulian C. Myocardial dysfunction and shock after cardiac arrest. BioMed Res Int 2015;2015.

8. Oksanen T, Skrifvars M, Wilkman E, Tierala I, Pettilä V, Varpula T. Postresuscitation hemodynamics during therapeutic hypothermia after out-of-hospital cardiac arrest with ventricular fibrillation: a retrospective study. Resuscitation 2014;85:1018-24.

9. Laurent I, Monchi M, Chiche JD, Joly LM, Spaulding C, Bourgeois B et al. Reversible myocardial dysfunction in survivors of out-of-hospital cardiac arrest. J Am Coll Cardiol 2002;40:2110-6.

10. Lemiale V, Dumas F, Mongardon N, Giovanetti O, Charpentier J, Chiche JD et al. Intensive care unit mortality after cardiac arrest: the relative contribution of shock and brain injury in a large cohort. Intensive Care Med 2013;39:1972-80.

11. Pellis T, Sanfilippo F, Ristagno G. The optimal hemodynamics management of post-cardiac arrest shock. Best Pract Res Clin Anaesthesiol 2015;29:485-95.

12. Ayoub IM, Radhakrishnan J, Gazmuri RJ. Targeting mitochondria for resuscitation from cardiac arrest. Crit Care Med 2008;36(Suppl):S440-6. 
13. Cooley DA, Reul GJ, Wukasch DC. Ischemic contracture of the heart: "stone heart." The Am J Cardiol 1972;29:575-7.

14. Niccoli G, Burzotta F, Galiuto L, Crea F. Myocardial no-reflow in humans. J Am Coll Cardiol 2009;54:281-92.

15. Hollenberg SM. Understanding stress cardiomyopathy. Intensive Care Med 2016;42:432-5.

16. Tang W, Weil MH, Sun S, Noc M, Yang L, Gazmuri RJ. Epinephrine increases the severity of postresuscitation myocardial dysfunction. Circulation 1995;92:3089-93.

17. Xie J, Weil MH, Sun S, Tang W, Sato Y, Jin X et al. High-energy defibrillation increases the severity of postresuscitation myocardial dysfunction. Circulation 1997;96:683-8.

18. Leng CT, Paradis NA, Calkins H, Berger RD, Lardo AC, Rent KC et al. Resuscitation after prolonged ventricular fibrillation with use of monophasic and biphasic waveform pulses for external defibrillation. Circulation 2000;101:2968-74.

19. Adrie C, Laurent I, Monchi M, Cariou A, Dhainaou JF, Spaulding C. Postresuscitation disease after cardiac arrest: a sepsis-like syndrome? Curr Opin Crit Care 2004;10:208-12.

20. Ruiz-Bailén M, Aguayo De Hoyos E, Ruiz-Navarro S, Díaz-Castellanos MÁ, RucabadoAguilar L, Gómez-Jiménez FJ et al. Reversible myocardial dysfunction after cardiopulmonary resuscitation. Resuscitation 2005;66:175-81.

21. van Diepen S, Katz JN, Albert NM, Henry TD, Jacobs AK, Kapur NK et al. Contemporary management of cardiogenic shock: a scientific statement from the American Heart Association. Circulation 2017;136:232-68.

22. Nolan JP, Soar J, Cariou A, Cronberg T, Moulaert VRM, Deakin CD et al. European Resuscitation Council and European Society of Intensive Care Medicine Guidelines for Postresuscitation Care 2015. Section 5 of the European Resuscitation Council Guidelines for Resuscitation 2015. Resuscitation 2015;95:202-22.

23. Gaieski DF, Band RA, Abella BS, Neumar RW, Fuchs BD, Kolansky DM et al. Early goaldirected hemodynamic optimization combined with therapeutic hypothermia in comatose survivors of out-of-hospital cardiac arrest. Resuscitation 2009;80:418-24.

24. Walters EL, Morawski K, Dorotta I, Ramsingh D, Lumen K, Bland D et al. Implementation of a post-cardiac arrest care bundle including therapeutic hypothermia and hemodynamic optimization in comatose patients with return of spontaneous circulation after out-of-hospital cardiac arrest: a feasibility study. Shock 2011;35:360-6.

25. Sunde K, Pytte M, Jacobsen D, Mangschau A, Jensen LP, Smedsrud C et al. Implementation of a standardised treatment protocol for post resuscitation care after out-of-hospital cardiac arrest. Resuscitation 2007;73:29-39. 
26. Kleinman ME, Perkins GD, Bhanji F, Billi JE, Bray JE, Callaway CW et al. ILCOR scientific knowledge gaps and clinical research priorities for cardiopulmonary resuscitation and emergency cardiovascular care: a consensus statement. Resuscitation 2018;127:132-46.

27. Vincent JL, de Backer D. Circulatory shock. N Engl J Med 2013;369:1726-34.

28. Mebazaa A, Combes A, van Diepen S, Hollinger A, Katz JN, Landoni G et al. Management of cardiogenic shock complicating myocardial infarction. Intensive Care Med 2018;44:760 73.

29. Annborn M, Bro-Jeppesen J, Nielsen N, Ullén S, Kjaergaard J, Hassager C et al. The association of targeted temperature management at 33 and $36^{\circ} \mathrm{C}$ with outcome in patients with moderate shock on admission after out-of-hospital cardiac arrest: a post hoc analysis of the Target Temperature Management trial. Intensive Care Med 2014;40:1210-9.

30. Uray T, Lamade A, Elmer J, Drabek T, Stezoski JP, Missé A et al. Phenotyping cardiac arrest: bench and bedside characterization of brain and heart injury based on etiology. Critical Care Med 2018;46:e508-15.

31. Ristagno G, Fumagalli F, Russo I, Tantillo S, Zani DD, Locatelli V et al. Postresuscitation treatment with argon improves early neurological recovery in a porcine model of cardiac arrest. Shock 2014;41:72-8.

32. Babini G, Ristagno G, Boccardo A, de Giorgio D, de Maglie M, Affatato R et al. Effect of mild hypercapnia on outcome and histological injury in a porcine post cardiac arrest model. Resuscitation 2019;135(February 2018):110-7.

33. Babini G, Grassi L, Russo I, Novelli D, Boccardo A, Luciani A et al. Duration of untreated cardiac arrest and clinical relevance of animal experiments: the relationship between the "noflow" duration and the severity of post-cardiac arrest syndrome in a porcine model. Shock. 2018;49.

34. Gonzalez MM, Berg RA, Nadkarni VM, Vianna CB, Kern KB, Timerman S et al. Left ventricular systolic function and outcome after in-hospital cardiac arrest. Circulation 2008;117:1864-72.

35. Ameloot K, Meex I, Genbrugge C, Jans F, Malbrain M, Mullens W et al. Accuracy of continuous thermodilution cardiac output monitoring by pulmonary artery catheter during therapeutic hypothermia in post-cardiac arrest patients. Resuscitation. 2014;85:1263-8.

36. Grand J, Kjaergaard J, Bro-Jeppesen J, Wanscher M, Nielsen N, Lindholm MG et al. Cardiac output, heart rate and stroke volume during targeted temperature management after out-ofhospital cardiac arrest: association with mortality and cause of death. Resuscitation 2019;142:136-43. 
37. Grand J, Bro-Jeppesen J, Hassager C, Rundgren M, Winther-Jensen M, Thomsen JH et al. Cardiac output during targeted temperature management and renal function after out-ofhospital cardiac arrest. J Crit Care 2019;54:65-73.

38. Stær-Jensen H, Sunde K, Olasveengen TM, Jacobsen D, Drægni T, Nakstad ER et al. Bradycardia during therapeutic hypothermia is associated with good neurologic outcome in comatose survivors of out-of-hospital cardiac arrest. Crit Care Med 2014;42:2401-8.

39. Thomsen JH, Hassager C, Bro-Jeppesen J, Søholm H, Nielsen N, Wanscher M et al. Sinus bradycardia during hypothermia in comatose survivors of out-of-hospital cardiac arrest - a new early marker of favorable outcome? Resuscitation 2015;89:36-42.

40. Oksanen T, Tiainen M, Vaahersalo J, Bendel S, Varpula T, Skrifvars M et al. Lower heart rate is associated with good one-year outcome in post-resuscitation patients. Resuscitation 2018;128:112-8.

41. Endoh H, Kamimura N, Honda H, Nitta M. Early prognostication of neurological outcome by heart rate variability in adult patients with out-of-hospital sudden cardiac arrest. Crit Care 2019;23:1-9.

42. Inoue A, Hifumi T, Yonemoto N, Kuroda Y, Kawakita K, Sawano H et al. The impact of heart rate response during 48-hour rewarming phase of therapeutic hypothermia on neurologic outcomes in out-of-hospital cardiac arrest patients. Crit Care Med 2018;46:e8818.

43. Grand J, Thomsen JH, Kjaergaard J, Nielsen N, Erlinge D, Wiberg S et al. Prevalence and prognostic implications of bundle branch block in comatose survivors of out-of-hospital cardiac arrest. Am J Cardiol 2016;118:1194-200.

44. Beylin ME, Perman SM, Abella BS, Leary M, Shofer FS, Grossestreuer A v. et al. Higher mean arterial pressure with or without vasoactive agents is associated with increased survival and better neurological outcomes in comatose survivors of cardiac arrest. Intensive Care Med 2013;39:1981-8.

45. Kilgannon JH, Roberts BW, Jones AE, Mittal N, Cohen E, Mitchell J et al. Arterial blood pressure and neurologic outcome after resuscitation from cardiac arrest. Crit Care Med 2014;42:2083-91.

46. Huang CH, Tsai MS, Ong HN, Chen W, Wang CH, Chang WT et al. Association of hemodynamic variables with in-hospital mortality and favorable neurological outcomes in post-cardiac arrest care with targeted temperature management. Resuscitation 2017;120:14652. 
47. Torgersen C, Meichtry J, Schmittinger CA, Bloechlinger S, Jakob SM, Takala J et al. Haemodynamic variables and functional outcome in hypothermic patients following out-ofhospital cardiac arrest. Resuscitation 2013;84:798-804.

48. Bro-Jeppesen J, Annborn M, Hassager C, Wise MP, Pelosi P, Nielsen N et al.

Hemodynamics and vasopressor support during targeted temperature management at $33^{\circ} \mathrm{C}$ versus $36^{\circ} \mathrm{C}$ after out-of-hospital cardiac arrest: a post hoc study of the target temperature management trial. Crit Care Med 2015;43:318-27.

49. Bro-Jeppesen J, Kjaergaard J, Søholm H, Wanscher M, Lippert FK, Møller JE et al. Hemodynamics and vasopressor support in therapeutic hypothermia after cardiac arrest: prognostic implications. Resuscitation 2014;85:664-70.

50. Laurikkala J, Wilkman E, Pettilä V, Kurola J, Reinikainen M, Hoppu S et al. Mean arterial pressure and vasopressor load after out-of-hospital cardiac arrest: associations with one-year neurologic outcome. Resuscitation 2016;105:116-22.

51. Jakkula P, Pettilä V, Skrifvars MB, Hästbacka J, Loisa P, Tiainen M et al. Targeting lownormal or high-normal mean arterial pressure after cardiac arrest and resuscitation: a randomised pilot trial. Intensive Care Med 2018;44:2091-101.

52. Ameloot K, de Deyne C, Eertmans W, Ferdinande B, Dupont M, Palmers PJ et al. Early goal-directed haemodynamic optimization of cerebral oxygenation in comatose survivors after cardiac arrest: the Neuroprotect post-cardiac arrest trial. Eur Heart J 2019;40:1804-14.

53. Chalkias A, Xanthos T. Post-cardiac arrest brain injury: pathophysiology and treatment. J Neurol Sci 2012;315:1-8.

54. Sundgreen C, Larsen FS, Herzog TM, Knudsen GM, Boesgaard S, Aldershvile J. Autoregulation of cerebral blood flow in patients resuscitated from cardiac arrest. Stroke; a journal of cerebral circulation. 2001;32:128-32.

55. Janiczek JA, Winger DG, Coppler P, Sabedra AR, Murray H, Pinsky MR et al. Hemodynamic resuscitation characteristics associated with improved survival and shock resolution after cardiac arrest. Shock 2016;45:613-9.

56. Levy B, Clere-Jehl R, Legras A, Morichau-Beauchant T, Leone M, Frederique G et al. Epinephrine versus norepinephrine for cardiogenic shock after acute myocardial infarction. $\mathbf{J}$ Am Coll Cardiol 2018;72:173-82.

57. Tarvasmäki T, Lassus J, Varpula M, Sionis A, Sund R, Køber L et al. Current real-life use of vasopressors and inotropes in cardiogenic shock - adrenaline use is associated with excess organ injury and mortality. Crit Care 2016;20:1-11. 
58. Hajjar LA, Teboul JL. Mechanical circulatory support devices for cardiogenic shock: state of the art. Crit Care 2019;23:1-10.

59. Yannopoulos D, Bartos JA, Aufderheide TP, Callaway CW, Deo R, Garcia S et al. The evolving role of the cardiac catheterization laboratory in the management of patients with out-of-hospital cardiac arrest: a scientific statement from the American Heart Association. Circulation 2019;139:e530-52.

60. Noc M, Fajadet J, Lassen JF, Kala P, Maccarthy P, Olivecrona GK et al. Invasive coronary treatment strategies for out-of-hospital cardiac arrest: a consensus statement from the European Association for Percutaneous Cardiovascular Interventions (EAPCI)/Stent for Life (SFL) groups. EuroIntervention 2014;10:31-7.

61. Kern KB, Lotun K, Patel N, Mooney MR, Hollenbeck RD, McPherson JA et al. Outcomes of comatose cardiac arrest survivors with and without ST-segment elevation myocardial infarction importance of coronary angiography. JACC-Cardiovasc Inte 2015;8:1031-40.

62. Lemkes JS, Janssens GN, van der Hoeven NW, Jewbali LSD, Dubois EA, Meuwissen M et al. Coronary angiography after cardiac arrest without ST-segment elevation. N Engl J Med 2019;380:1397-407. 


\section{NOTES}

Conflicts of interest. The authors certify that there is no conflict of interest with any financial organization regarding the material discussed in the manuscript.

Authors' contributions. Giovanni Babini conceptualized, drafted, revised and submitted the manuscript. Koen Ameloot contributed to the writing of the manuscript. Markus B. Skrifvars conceptualized and contributed to the writing of the manuscript. All authors read and approved the final manuscript.

\section{TABLES}

Table I.- Relevant recent literature on post-resuscitation cardiac function

Table II.-Proposed phenotypes of cardiogenic shock in patients resuscitated from cardiac arrest

\section{TITLES OF FIGURES}

Figure 1.-Approach to post-cardiac arrest myocardial dysfunction. 
Table I.- Relevant recent literature on post-resuscitation cardiac function

\begin{tabular}{|c|c|c|c|c|}
\hline \multicolumn{5}{|c|}{ INTERVENTION STUDIES } \\
\hline Study & Design and patients included & Inclusion criteria & Intervention groups & Main results \\
\hline $\begin{array}{l}\text { COMACARE trial } \\
\text { Jakkula et al. }\end{array}$ & $\begin{array}{l}\text { Randomized clinical trial, } \\
\mathrm{n}=123\end{array}$ & $\begin{array}{l}\text { Comatose, ventilated, adult patients } \\
\text { resuscitated from VF/pVT OHCA } \\
\text { Confirmed or suspected cardiac } \\
\text { cause } \\
\text { ROSC within } 10-45 \text { min from OHCA }\end{array}$ & $\begin{array}{l}\text { Low-normal }(65-75 \mathrm{mmHg}) \text { vs. } \\
\text { high-normal }(80-100 \mathrm{mmHg}) \mathrm{MAP}\end{array}$ & $\begin{array}{l}\text { Targeting a specific range of MAP is feasible. These MAP } \\
\text { range are safe. No improvements in NSE after } 48 \text { hours } \\
\text { from OHCA were observed }\end{array}$ \\
\hline $\begin{array}{l}\text { NEUROPROTECT } \\
\text { post-CA trial } \\
\text { Ameloot et al. }\end{array}$ & $\begin{array}{l}\text { Randomized clinical trial, } \\
\mathrm{n}=112\end{array}$ & $\begin{array}{l}\text { Comatose, adult patients resuscitated } \\
\text { from OHCA of resumed cardiac } \\
\text { cause } \\
\text { Sustained ROSC for }>20 \mathrm{~min}\end{array}$ & $\begin{array}{l}\text { EGDHO (MAP } 85-100 \mathrm{mmHg} \\
\text { SvO2 65-75\%) vs. MAP } 65 \mathrm{mmHg}\end{array}$ & $\begin{array}{l}\text { EGDHO was safe, improved cerebral oxygenation } \\
\text { measured by NIRS, but did not result in an improvement in } \\
\text { neurological outcome }\end{array}$ \\
\hline \multicolumn{5}{|c|}{ OBSERVATIONAL STUDIES } \\
\hline Study & Design and patients included & Inclusion criteria & Main results & \\
\hline Kilgannon et al. & $\begin{array}{l}\text { Prospective observational } \\
\text { study, } n=151\end{array}$ & $\begin{array}{l}\text { Comatose, adult patients resuscitated } \\
\text { from IHCA and OHCA }\end{array}$ & $\begin{array}{l}\text { Time-weighted average MAP pressu } \\
\text { threshold greater than } 70 \mathrm{mmHg}\end{array}$ & was associated with good neurologic outcome at a MAP \\
\hline Oksanen et al. ${ }^{40}$ & $\begin{array}{l}\text { Preplanned sub-study of the } \\
\text { FINNRESUSCI study, } n=504\end{array}$ & $\begin{array}{l}\text { Adults patients resuscitated from } \\
\text { OHCA }\end{array}$ & Lower heart rate was independently & ssociated with one-year good neurological outcome \\
\hline Thomsen et al. ${ }^{39}$ & Retrospective study, $\mathrm{n}=234$ & $\begin{array}{l}\text { Comatose, adult patients resuscitated } \\
\text { from OHCA of presumed cardiac } \\
\text { cause } \\
\text { Sustained ROSC for }>20 \mathrm{~min}\end{array}$ & $\begin{array}{l}\text { Synus bradycardia }(\mathrm{HR}<50 \mathrm{bpm}) \mathrm{d} \\
\text { 180-day mortality rate }\end{array}$ & ring $\mathrm{TTM}$ at $33^{\circ} \mathrm{C}$ was independently associated with lower \\
\hline Grand et al. ${ }^{36}$ & $\begin{array}{l}\text { Post-hoc analysis of the TTM } \\
\text { trial, } n=151\end{array}$ & $\begin{array}{l}\text { Comatose, adult patients resuscitated } \\
\text { from OHCA of presumed cardiac } \\
\text { cause } \\
\text { Sustained ROSC for }>20 \mathrm{~min}\end{array}$ & $\begin{array}{l}\text { Cardiac output was not an associate } \\
\text { death. If lactate is normal, low cardi } \\
\text { mortality }\end{array}$ & $\begin{array}{l}\text { with mortality, independently from the presumed cause of } \\
\text { index during TTM seems benign and not associated with }\end{array}$ \\
\hline Grand et al. ${ }^{37}$ & $\begin{array}{l}\text { Post-hoc analysis of the TTM } \\
\text { trial, } n=152\end{array}$ & $\begin{array}{l}\text { Comatose, adult patients resuscitated } \\
\text { from OHCA of presumed cardiac } \\
\text { cause } \\
\text { Sustained ROSC for }>20 \mathrm{~min}\end{array}$ & $\begin{array}{l}\text { Cardiac output is not an independen } \\
\text { Heart rate, MAP and lactate were in }\end{array}$ & $\begin{array}{l}\text { predictor of AKI } \\
\text { ependently associated with AKI }\end{array}$ \\
\hline
\end{tabular}

AKI: acute kidney injury; CA: cardiac arrest; EGDHO: early goal-directed haemodynamic optimization; IHCA: in-hospital cardiac arrest; OHCA: out-of-hospital cardiac arrest; MAP: mean arterial pressure; NIRS: near infra-red spectroscopy; NSE: neural serum enolase; pVT: pulseless ventricular tachycardia; ROSC: return of spontaneous circulation; TTM: target temperature management; VF: ventricular fibrillation. 
Table II.- Proposed phenotypes of cardiogenic shock in patients resuscitated from cardiac arrest

\begin{tabular}{|c|c|c|}
\hline & BENIGN & MALIGN \\
\hline Arterial pressure & $\begin{array}{l}\mathrm{MAP}>65-70 \mathrm{mmHg} \\
\text { No/moderate vasopressor support }\end{array}$ & $\begin{array}{l}\text { MAP }<60-65 \mathrm{mmHg} \\
\text { High dosage of vasopressor for prolonged time }\end{array}$ \\
\hline $\begin{array}{l}\text { Heart rate and cardiac } \\
\text { rhythm }\end{array}$ & $\begin{array}{l}\text { Sinus bradycardia during TTM } \\
\text { Increase after rewarming within } \\
\text { physiological limits }\end{array}$ & $\begin{array}{l}\text { Constantly elevated } \\
\text { No significant changes during the various phases of TTM } \\
\text { Various degree of dysrhythmia (e.g. rapid atrial fibrillation, sustained } \\
\text { ventricular ectopy, ventricular tachycardia, recurrent CA) }\end{array}$ \\
\hline Cardiac output & Recovery in the first 3 days after admission & $\begin{array}{l}\text { Progressive decrease } \\
\text { Need for mechanical circulatory support }\end{array}$ \\
\hline Diuresis & $>0.5 \mathrm{ml} \mathrm{kg}-1 \mathrm{~h}^{-1}$ & $\begin{array}{l}<0.5 \mathrm{ml} \mathrm{kg}^{-1} \mathrm{~h}^{-1} \\
\text { Need for renal replacement therapy }\end{array}$ \\
\hline Lactate & $\begin{array}{l}\text { Constant clearance } \\
\text { Decrease to low/normal value within 6-12 } \\
\text { hours }\end{array}$ & $\begin{array}{l}\text { Slow clearance } \\
\text { Elevated for several days }\end{array}$ \\
\hline $\begin{array}{l}\text { Central/mixed venous } \\
\text { saturation }\end{array}$ & $>65-70 \%$ & $<60-65 \%$ or abnormally high \\
\hline
\end{tabular}

CA: cardiac arrest; MAP: mean arterial pressure; TTM: target temperature management. 


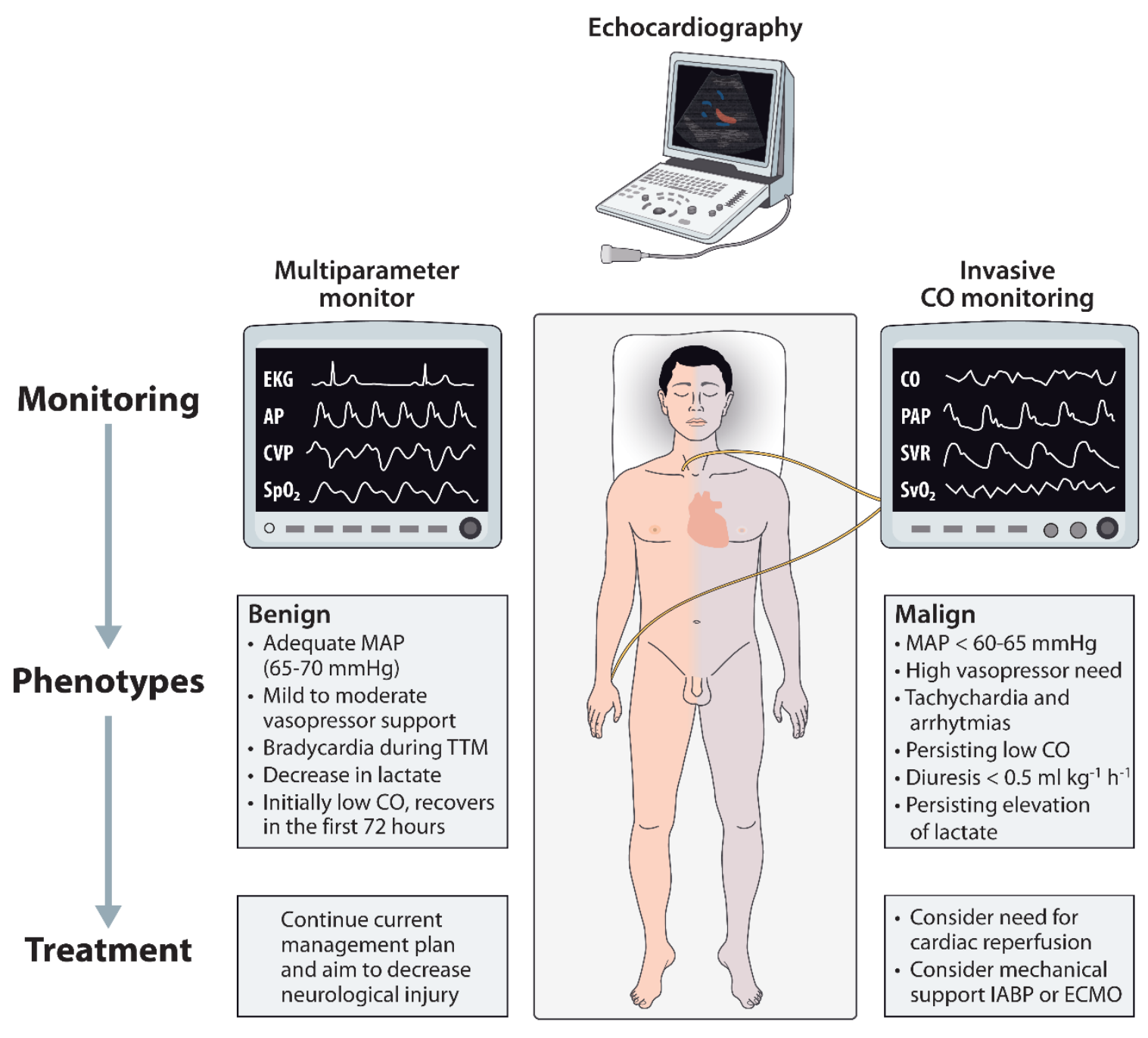

Figure 1.-Approach to post-cardiac arrest myocardial dysfunction. 